\title{
Feminismos e Gênero em tempos de mal-estar
}

Feminism and Gender in Troubled Times

\author{
Tânia Regina de Oliveira Ramos ${ }^{1}$ (iD) 0000-0002-2477-0419

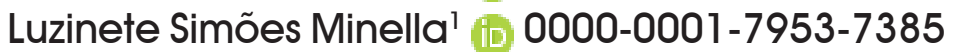 \\ Mara Coelho de Souza Lago' ${ }^{1}$ (i) 0000-0001-5111-8699 \\ Cristina Scheibe Wolff ${ }^{1}$ (id 0000-0002-7315-1112
}

'Universidade Federal de Santa Catarina, Florianópolis, SC, Brasil. 88040-900

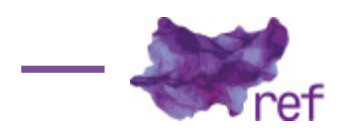

\begin{abstract}
A Revista Estudos Feministas remete este terceiro número do ano de 2019 a um ensaio de Florestan Fernandes (1979) sobre os profundos anos 70 onde ele pergunta: qual o papel do intelectual na sociedade brasileira nesse instante? Quatro décadas depois, a REF volta-se para seus instantes onde falas, discursos, pesquisas, aulas, artigos, ensaios, entrevistas, resenhas, respondem pelo seu importante papel de ser denúncia e combate através de uma sólida produtividade em perspectivas teóricas e críticas revolucionárias que se estendem do final do século XX a estas primeiras décadas do XXI. Sem o ardor das denúncias cotidianas - ainda que válidas - das redes sociais e do jornalismo do tempo presente, a REF é um local de combate pelo alcance e profundidade do espaço histórico que ela construiu desde 1992 e vem construindo por meio de suas 72 edições, em abordagens interdisciplinares no campo das teorias de gênero e da crítica feminista. Não só se contrapõe à censura não mais velada e à repressão cultural, mas transforma a palavra e a produção acadêmica feminista e plural pelo acesso democrático a um conhecimento adquirido em sua maioria em institutos de pesquisa, em universidades públicas e/ou de qualidade a temas importantes como violência, cultura, arte, diversidade, preconceito, etnias, mulheres, corpos.

Vivemos tempos de revelações das farsas políticas e jurídicas utilizadas para a ascensão ao poder de um sistema neoliberal empenhado em destruir qualquer organização, instituição ou política de proteção a direitos humanos, quaisquer resquícios de ações voltadas para o bemestar social ou proteção dos interesses de trabalhadoras/es e a garantia de direitos das classes populares. Políticas que acabam por atingir todo o restante da população, a cultura, a ciência, a produção industrial, a tecnologia, preservando apenas os interesses e privilégios de classe das elites brasileiras ligadas principalmente ao setor financeiro, caracterizadas por Jessé de SOUZA (2017) como elites do atraso.

Continua, assim, sendo sofrido falar do Brasil nos últimos meses deste ano de 2019 e a retomada do alerta de Angela DAVIS (2018) "a liberdade é uma luta constante" segue sendo estratégia potente. Pensar em feminismos, em gênero, na exaltação de modelos reeditados de masculinidades dominadoras, hostis, armadas para o combate às mulheres, aos pobres, aos negros, aos povos indígenas e quilombolas, às pessoas homossexuais e transexuais, continua sendo fonte de mal-estar, mas de resistência necessária. Resistência a medidas que ameaçam a soberania nacional, o meio ambiente, a proteção do território brasileiro e suas populações tradicionais, a garantia de terras para o trabalho camponês de produção de alimentos, a assistência aos extratos mais vulneráveis da população. Resistência à criminalização de movimentos sociais, aos retrocessos nas conquistas feministas e de gênero.

Não causa surpresa o fato de que a maioria dos textos publicados na Seção Artigos que inicia a Revista Estudos Feministas esteja, neste número, voltada para a questão da violência. Violências de gênero em suas inúmeras formas, desde a violência obstétrica, com tentativas atuais de deslegalização, no direito brasileiro, ao silenciamento das vozes de mulheres e sujeitos
\end{abstract}


em diferentes lugares de vivências e atuações. Artigos sobre variadas formas de violência de gênero: violência doméstica, violências contra feministas na internet; violência nos textos jurídicos; com relação ao estado em diversos países da América Latina, com destaque para o caso da Bolívia; a violência contra as mulheres nos livros escolares, violência sexual, de educação e de gênero. O assédio sexual nas ruas, abordado como um tipo de violência contra as mulheres em texto que se fundamenta no debate feminista, no enfoque interseccional e nas discussões sobre crimes de ódio. São várias as abordagens e perspectivas sobre essa temática tão fundamental para o feminismo e os movimentos de mulheres no mundo inteiro. É significativo que neste momento político a questão da violência seja problematizada nas publicações acadêmicas feministas, na medida em que os fundamentalismos e as ideias conservadoras colocam a violência de gênero em nosso cotidiano no Brasil e em muitas partes do mundo com muita força. Este é um momento em que estamos, as mulheres, as e os homossexuais, as pessoas trans, mais que nunca, vulneráveis a violências em nossos cotidianos, e elas se somam às violências simbólicas, virtuais e culturais. Falar dessas violências, analisá-las, debatê-las, é também uma forma de encontrar maneiras de resistir e de superar esse movimento conservador, buscando soluções que permitam a todas as pessoas, de todas as raças, classes, idades, nacionalidades, orientações sexuais, etnias, crenças, conviver de outra maneira.

Esta edição da REF traz ainda muitos artigos literários feministas, como o de mulheres blogueiras negras que analisam processos relacionais e éticos de subjetivação que se produzem nas experiências de tornar-se negra em escritas de si. Seis desses artigos transitam entre nomes próprios e corporeidades e estão relacionados a algumas tendências do pensamento no contexto contemporâneo voltadas a dimensões fundamentais da experiência humana. Noções de território, linguagem, corpo, arte, comunicação, passam por Maya Angelou e sua jornada como jovem mulher negra; percorrem a Colômbia e suas mulheres transgêneros produzindo arte; buscam as micropolíticas do desejo nos corpos infectados pela AIDS e nas dores do vir a ser da maternidade mediada e testemunhada pelas doulas; transpõem as narrativas através das frágeis fronteiras da ficção e da biografia; alcançam a produção social do espaço de mulheres da Argentina, Colômbia e Chile, as quais, na tentativa de superar aquilo que as vitimou, transformam a arte em instrumento de utilização política e como o ensino das artes visuais, aproximado de discussões de gênero, se mantém como experiência criativa de resistência. Todas estas leituras permitem entender como os discursos de representação, se atingidos pela intervenção feminista, deixam de ser referência estável para serem poéticas da verdade, práticas artísticas, dicções literárias, riscos de bordados, com direitos e avessos, realismos afetivos porque nos pungem, nos sensibilizam.

Outros temas atuais foram tratados nos artigos deste número da Revista. Reflexão sobre o poliamor, visto como a vivência de múltiplas relações afetivas e sexuais concomitantes, igualitárias e consensuais, em análise de textos que destacam as dificuldades em estabelecer relações deste tipo em contextos de desigualdades de gênero, raças, classes. Artigo que toma como síndrome cultural norte-americana a disforia de gênero, categoria construída sobre concepções psiquiátricas fundamentadas no pensamento binário, questionada na análise dos autores deste texto, pela alteridade radical da travesti brasileira. O estudo de organizações feministas, revelando formas organizacionais não dissonantes, não binárias, não reprodutoras de diferenças sexuais, que podem servir como modelos para a implementação de políticas públicas em nossos países. Dois artigos discutem as relações entre gênero e história focalizando o contexto colonial; o primeiro explora a documentação histórica das Missões Indígenas-Jesuíticas ocorridas entre 1609 e 1750, além de sítios arqueológicos, no intuito de analisar as representações sobre as mulheres indígenas; inspirado na arqueologia e na genealogia foucaultiana, aliada a uma perspectiva atenta às interações entre gênero, raça e sexualidade; o seguinte investiga as narrativas sobre o Corpo Colonial nos Museus dos Descobrimentos Portugueses, ao observar o modo como os discursos das Exposições do Império Português é construído, desconstruído e reconstruído. Este número da REF traz um estudo que estabelece relações entre educação e gênero, sobre profissionais da educação básica que realizaram o Curso Gênero e Diversidade na Escola, com informações sobre suas percepções acerca dos conteúdos do curso, abordados através de grupo focal; uma investigação sobre mulheres empreendedoras, utilizando-se de técnicas etnográficas e de entrevistas em profundidade, com resultados submetidos à análise de discurso. Há ainda um artigo sobre o movimento feminista chileno e sua cronologia histórica, que nos ajuda a pensar sobre o feminismo na América Latina como um todo, compreender suas idas e vindas, seus percalços, mas também a novidade, a criação de outras formas de luta e de resistência. Luta e resistência que se expressam nas nove resenhas reunidas que falam de publicações recentes, de obras e textos, onde se pode pensar como o 'fazer-se' livro promove possibilidades de transformação e permanência de nomes próprios nas capas, títulos, temas como transgressões, descentramentos, subversão, resistência, preconceitos, linguagens e feminismos.

O ensaio publicado na Seção Ponto de Vista problematiza os discursos biológicos sobre as relações corpo e gênero, discutindo noções de "corpo ideal" e de "corpos à margem", ponderando 
a respeito de seus impactos sobre o ensino de biologia a partir de enfoque decolonial. Na mesma Seção foi publicada a entrevista com a artista feminista Ciça, que se notabilizou com seus cartuns desde os anos 1970, no combate à ditadura.

A Seção Temática foi organizada pela antropóloga brasileira Laura Moutinho, em conjunto com a antropóloga moçambicana Esmeralda Mariano. No artigo em que faz a apresentação da Seção, Moutinho (2019) detalha aspectos da pesquisa realizada, com a formação de extensa rede de pesquisadoras oriundas de diferentes regiões do Brasil e da África, envolvendo Moçambique e outros países do Continente Africano. Um relevante trabalho de investigação incentivado e possibilitado por edital do CNPq, com a participação de várias instituições brasileiras e africanas, principalmente, cujos resultados dão testemunho da importância da produção das universidades para o desenvolvimento da ciência nos países que as abrigam. E aqui estamos falando de universidades públicas e de ciências humanas, atualmente sob ataques no Brasil. A pesquisa, que resultou adicionalmente em extensa produção de artigos teve, segundo a autora, o intuito de produzir conhecimentos numa perspectiva Sul-Sul, pela comparação entre países com experiências de colonização, no interesse de encontrar meios de ultrapassar formas perenes de produção de desigualdades.

O artigo-apresentação de Moutinho sintetiza e exemplifica a crueza do desmanche de organismos institucionais responsáveis pela pesquisa e o ensino superior no Brasil, CNPq e CAPES, quando detalha a interrupção do "Programa de Cooperação Temática em Matéria de Ciência e Tecnologia" - PROÁFRICA, criado em 2004 pelo CNPq.

Entre o combate e a denúncia, a esperança e a desesperança, o ano de 2019 terminará com mais mulheres sendo assassinadas; com a presidência da república vetando a obrigação de hospitais de notificar suspeitas de violência contra a mulher; com crianças sendo mortas e nomes próprios se tornando cicatrizes e tatuagens: Marielle e Agatha, tão semelhantes e tão próximas desde o território em que ocupavam. Passado e presente sem futuro. Quem as matou? 2019 termina com a atriz de 90 anos, Fernanda Montenegro, ícone da luta das mulheres no campo da arte, sendo chamada de sórdida e mentirosa por vozes antidemocráticas, desrespeitosas, no mesmo tom machista e autocrata que a jornalista Nina Lemos (2019) denuncia em seu artigo "Greta, 16, alvo de bullying de homens de meia idade. Quem tem 'problema'?", publicado em 27 de setembro de 2019. Nele a jornalista constata e contesta que Greta Thunberg, a jovem sueca de 16 anos, ativista contra o aquecimento global, foi chamada de "Retardada mental", "Feia com um cabelo de milho" e foi assim avaliada: "Ela precisa de um namorado. Isso é falta de sexo". Nina Lemos deixa claro que a jovem sueca está sofrendo bullying pesado no Brasil e fora dele e não por adolescentes, mas por homens adultos, de meia idade.

A esperança, porém, continua.

De 28 de outubro a $1^{\circ}$ novembro de 2019, a Revista Estudos Feministas participa da Semana Especial no Blog SciELO em Perspectiva - Humanas, apresentando debates acadêmicos e pesquisas que abordam temas e problemas contemporâneos publicados na Revista. Violência de gênero, racismo, identidades queer são assuntos que estarão em destaque na Semana da REF, ao lado de informações sobre a Revista, sua trajetória e as perspectivas do grupo editorial. Durante a Semana, leitores e leitoras do Blog vão conhecer os textos e vídeos que trazem fragmentos e memórias dessa história, com olhos no passado, sem perder o foco nos desafios do presente e nos últimos números publicados.

O primeiro dia será de apresentação, com texto e vídeo narrando, de modo complementar, a trajetória da Revista desde os primeiros anos no Rio de Janeiro até a chegada em Santa Catarina e os desafios assumidos pela equipe editorial da UFSC. No segundo dia, o assunto será o debate político e o ativismo no conteúdo dos dossiês da Revista. Em vídeo, as editoras falarão sobre as seções temáticas e o trabalho em rede como metodologia de publicação. No terceiro dia, debateremos os desafios da internacionalização para os periódicos científicos. E no quarto dia abordaremos o humor como fonte de pesquisa acadêmica, conversando sobre os quadrinhos da cartunista feminista Ciça, uma das mais populares do Brasil nos anos de resistência à ditadura e de expansão dos feminismos. Por último, traremos uma aproximação entre África e Brasil, cruzando histórias e teorias, trabalhando com os artigos da Seção Temática publicada neste número da REF. O último post desse conjunto fala sobre o presente e o futuro, sempre pensados em rede, pelas editoras da Revista Estudos Feministas.

Os dez textos da Semana da REF foram escritos por Ana Maria VEIGA (2019), professora de História da UFPB e editora de divulgação da Revista. Os vídeos foram roteirizados, produzidos e editados por Ana Veiga, contando com a parceria da cinegrafista e editora Fernanda Backendorf (graduanda em Cinema/UFSC), que fez parte da equipe REF durante os últimos dois meses.

Convidamos leitoras e leitores a acompanharem a trajetória, as histórias e informações sobre a REF no blog https://humanas.blog.scielo.org/semanasespeciais/. E também a seguir a Revista nas redes sociais.

Lembramos que entre os dias 26 e 31 de julho de 2020 realizaremos na Universidade Federal de Santa Catarina o Seminário Internacional Fazendo Gênero 12 - "Lugares de fala: 
direitos, diversidades, afetos". Pesquisadoras, estudantes, ativistas, artistas, professoras e interessadas nas questões que envolvem rodas de conversa, mesas redondas, conferências, oficinas, atividades culturais, exposição de pôsteres, lançamentos e que já conta com propostas de mais de 180 Simpósios Temáticos inscritos. A participação da academia e dos movimentos sociais num evento desta natureza se torna mais relevante diante dos retrocessos que os movimentos ligados aos direitos humanos em geral têm enfrentado, à medida que visibilizará - pelas falas e publicações - as lutas contra preconceitos, discriminações, racismos, violências físicas extremas e simbólicas entre outros ataques (que, infelizmente, têm se tornado assustadoramente comuns) às mulheres, aos negros, aos indígenas, aos LGBTs, aos moradores de rua, às comunidades periféricas urbanas, aos trabalhadores sem terra e outros segmentos da população brasileira, bem como a linguagem, a arte, as políticas públicas, a interdisciplinaridade como formas de resistência.

Anunciamos ainda que, em 2020, será realizado mais um Congresso Mundos de Mulheres, Women's Worlds Congress, registrando a força e a representatividade deste evento que aconteceu no Brasil, mais precisamente na UFSC, em Florianópolis, em 2017. A $13^{a}$ edição deste congresso, que pretende o diálogo entre ativismos e academia em âmbito mundial sobre a questão das mulheres, dos feminismos e do gênero, será realizada em Maputo, Moçambique, em setembro de 2020. Uma coalizão de universidades e movimentos de mulheres está preparando o evento e o Instituto de Estudos de Gênero (IEG/UFSC) criou uma Comissão Pró-Moçambique para motivar e organizar a ida de uma representativa delegação brasileira. E é do olhar para a sua África e das mãos da poeta, que participou da troca de bandeiras na passagem do Congresso Mundos de Mulheres do Brasil para Moçambique, ao final do Seminário Internacional Fazendo Gênero, em 2017 , que a Revista Estudos Feministas amarra e sustenta laços na voz da resistência de Conceição Evaristo (2017, p. 19):

\author{
No fundo do calumbé \\ nossas mãos sempre e sempre \\ espalmam nossas outras mãos \\ moldando fortalezas esperanças, \\ heranças nossas divididas com você: \\ malungo, brother, irmão.
}

\title{
Referências
}

DAVIS, Angela. A liberdade é uma luta constante. São Paulo: Boitempo, 2018.

EVARISTO, Conceição. "Malungo, brother, irmão”. In: EVARISTO, Conceição. Poemas da Recordação e outros movimentos. Rio de Janeiro: Malê, 2017.

FERNANDES, Florestan. "Tarefas dos intelectuais na revolução democrática”. In: FELIX, Moacyr et al. (Orgs.). Revista Civilização Brasileira, Rio de Janeiro, Civilização Brasileira, v. 14, p. 25, 1979.

LEMOS, Nina. "Greta, 16, alvo de bullying de homens de meia idade. Quem tem 'problema'?". Universa. 2019. Disponível em https://ninalemos.blogosfera.uol.com.br/2019/09/27/greta-16-alvode-bullying-de-homens-de-meia-idade-quem-tem-problema/. Acesso em 12/12/2019.

MOUTINHO, Laura. "Cooperação internacional, parcerias acadêmicas e afeto na perspectiva SulSul”. Revista Estudos Feministas, v. 27, n. 3, 2019.

SOUZA, Jessé. A elite do atraso: da escravidão à Lava Jato. Rio de Janeiro: Casa da Palavra; Leya, 2017.

VEIGA, Ana Maria. "Textos para a Semana da Revista Estudos Feministas". SciELO em Perspectiva/ Humanas. SciELO, 2019. Disponível em https://humanas.blog.scielo.org/semanasespeciais/.

VEIGA, Ana Maria; BACKENDORF, Fernanda. "Vídeos para a Semana da Revista Estudos Feministas". SciELO em Perspectiva/Humanas. SciELO, 2019. Disponível em https://humanas.blog.scielo.org/ semanasespeciais/. 
Tânia Regina de Oliveira Ramos (taniareginaoliveiraramos@gmail.com) é doutora em Literaturas de Língua Portuguesa pela Pontifícia Universidade Católica do Rio de Janeiro. Possui graduação em Letras pela Universidade Federal de Santa Catarina, mestrado e doutorado em Literaturas de Língua Portuguesa pela Pontifícia Universidade Católica do Rio de Janeiro. Atualmente é Professora Titular e coordena o núcleo Literatura e Memória da UFSC, núcleo com projetos aprovados pela FAPESC e CNPq. Faz parte da Coordenação Geral da Revista Estudos Feministas e do Conselho Editorial das revistas UniLetras, Mafuá Ciências e Letras, Literatura Hoje, Signótica e Anuário de Literatura. É professora de Literatura Brasileira e Estudos Literários nos Cursos de Graduação e Pós-Graduação em Letras e Literatura na UFSC. Atua, pesquisa e publica nas linhas de pesquisa História e Memória, escritas de si e gênero.

Luzinete Simões Minella (simoesluzinete@gmail.com) é doutora em Sociologia pela Universidad Nacional Autónoma de Mexico (UNAM, 1989), graduada (1972) e mestre em Ciências Sociais pela UFBA (1977). Realizou estágio de pós-doutorado no Núcleo de Estudos de População da Universidade Estadual de Campinas (NEPO/Unicamp, 1998). Atualmente é Professora Adjunta IV aposentada da Universidade Federal de Santa Catarina (UFSC), atuando como professora voluntária no PPG Interdisciplinar em Ciências Humanas, onde coordena a área de Estudos de Gênero. Integra a equipe do Instituto de Estudos de Gênero (IEG), participando de vários dos seus projetos (eventos, publicações, cursos etc). Publicou vários artigos em periódicos de ampla circulação, livros, trabalhos completos em anais de eventos etc. Assumiu a coordenação editorial da Revista Estudos Feministas entre 2001 e 2004 e entre 2007 e 2008, quando passou a integrar a editoria de artigos. Voltou a fazer parte desta coordenação em dezembro de 2016. É membro da Rede Iberoamericana de Ciencia, Tecnología y Género. Tem realizado pesquisas principalmente nas seguintes áreas: participação das mulheres nas ciências (na interface com a crítica feminista à ciência, os estudos sociais da ciência e à história da ciência), gênero e saúde reprodutiva, gênero e infância, saúde mental. Orientou trabalhos de conclusão de curso e tem orientado dissertações e teses, principalmente nessas áreas.

Mara Coelho de Souza Lago (maralago07@gmail.com) é doutora em Psicologia da Educação pela Universidade Estadual de Campinas e Professora Emérita da Universidade Federal de Santa Catarina. Possui graduação em Pedagogia pela Universidade do Estado de Santa Catarina (1967), mestrado em Antropologia Social pela Universidade Federal de Santa Catarina (1983). Atualmente é Professora Titular aposentada da Universidade Federal de Santa Catarina/ UFSC, atuando como docente voluntária no Programa de Pós-Graduação em Psicologia/ PPGP e no Programa de Pós-Graduação Interdisciplinar em Ciências Humanas/PPGICH. Tem experiência na área de Psicologia, com ênfase em Psicologia Social, atuando principalmente nos temas gênero, gerações, subjetividades, modos de vida, com enfoque interdisciplinar. Participa do Instituto de Estudos de Gênero - IEG/UFSC e da coordenação editorial da Revista Estudos Feministas.

Cristina Scheibe Wolff (cristiwolff@gmail.com) é doutora em História Social pela Universidade de São Paulo (1998). Possui graduação em História pela Universidade Federal de Santa Catarina (1988), mestrado em História pela Pontifícia Universidade Católica de São Paulo (1991). Em 2004/2005 realizou pós-doutorado na Université Rennes 2, na França, e entre 2010 e 2011 , no Latin American Studies Center da University of Maryland, em College Park, Estados Unidos da América. Ocupou a Cátedra Fulbright de Estudos Brasileiros na University of Massachusetts em Amherst (set-dez 2017) e foi pesquisadora convidada no Laboratoire Arenes - Université Rennes 2 (janeiro a julho 2018). Atualmente é Professora Titular do Departamento de História da Universidade Federal de Santa Catarina. É integrante do Laboratório de Estudos de Gênero e História (LEGH) e do Instituto de Estudos de Gênero da UFSC e uma das coordenadoras editoriais da Revista Estudos Feministas (2006-2009 e 2011 -atual). Foi coordenadora do Programa de Pós-Graduação em História da Universidade Federal de Santa Catarina. Atua ainda no Programa de Pós-Graduação Interdisciplinar em Ciências Humanas e no Mestrado Profissional de Ensino de História. Foi a coordenadora geral do Fazendo Gênero 11 e 13 Women's Worlds Congress, realizado na UFSC em 2017 . Tem experiência na área de História, com ênfase em História das Mulheres e do Gênero, atuando principalmente nos seguintes temas: gênero, memória, guerrilha, resistência às ditaduras no Cone Sul. 


\section{COMO CITAR ESSE ARTIGO DE ACORDO COM AS NORMAS DA REVISTA}

RAMOS, Tânia Regina Oliveira; MINELLA, Luzinete Simões; LAGO, Mara Coelho de Souza; WOLFF, Cristina Scheibe. "Feminismos e gênero em tempos de mal-estar". Revista Estudos Feministas, Florianópolis, v. 27, n. 3, e68012, 2019.

\section{CONTRIBUIÇÃO DE AUTORIA}

Elaboração e redação coletiva

\section{FINANCIAMENTO}

Não se aplica

\section{CONSENTIMENTO DE USO DE IMAGEM}

Não se aplica

APROVAÇÃO DE COMITÊ DE ÉTICA EM PESQUISA

Não se aplica

\section{CONFLITO DE INTERESSES}

Não se aplica

\section{LICENÇA DE USO}

Este artigo está licenciado sob a Licença Creative Commons CC-BY Internacional. Com essa licença você pode compartilhar, adaptar, criar para qualquer fim, desde que atribua a autoria da obra.

\section{HISTÓRICO}

Recebido em 14/10/2019

Aceito em 15/10/2019

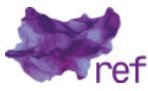

